\title{
Physician participation in clinical research and trials: issues and approaches
}

This article was published in the following Dove Press journal:

Advances in Medical Education and Practice

7 March 201I

Number of times this article has been viewed

\author{
Sayeeda Rahman' \\ Md Anwarul Azim \\ Majumder' \\ Sami F Shaban ${ }^{2}$ \\ Nuzhat Rahman ${ }^{3}$ \\ Moslehuddin Ahmed ${ }^{4}$ \\ Khalid Bin Abdulrahman ${ }^{5}$ \\ Urban JA D'Souza ${ }^{6}$ \\ 'Department of Clinical Sciences, \\ School of Life Sciences, University \\ of Bradford, West Yorkshire, Bradford, \\ UK; ${ }^{2}$ Department of Medical \\ Education, Faculty of Medicine \\ and Health Sciences, UAE University, \\ Al-Ain, United Arab Emirates; \\ ${ }^{3}$ Department of Nutrition Sciences, \\ University of Alabama at Birmingham, \\ Birmingham, AL, USA; ${ }^{4}$ Department \\ of Community Medicine, Uttara \\ Adhunik Medical College, Dhaka, \\ Bangladesh; ${ }^{5}$ Department of Family \\ Medicine and Medical Education, \\ College of Medicine, Al-Imam \\ University, Riyadh, Saudi Arabia; \\ ${ }^{6}$ Department of Post Graduate \\ Studies, School of Medicine, \\ University Malaysia Sabah, \\ Kota Kinabalu, Sabah, Malaysia
}

\begin{abstract}
The rapid development of new drugs, therapies, and devices has created a dramatic increase in the number of clinical research studies that highlights the need for greater participation in research by physicians as well as patients. Furthermore, the potential of clinical research is unlikely to be reached without greater participation of physicians in research. Physicians face a variety of barriers with regard to participation in clinical research. These barriers are systemor organization-related as well as research- and physician-related. To encourage physician participation, appropriate organizational and operational infrastructures are needed in health care institutes to support research planning and management. All physicians should receive education and training in the fundamentals of research design and methodology, which need to be incorporated into undergraduate medical education and postgraduate training curricula and then reinforced through continuing medical education. Medical schools need to analyze current practices of teaching-learning and research, and reflect upon possible changes needed to develop a 'student-focused teaching-learning and research culture'. This article examines the barriers to and benefits of physician participation in clinical research as well as interventions needed to increase their participation, including the specific role of undergraduate medical education. The main challenge is the unwillingness of many physicians and patients to participate in clinical trials. Barriers to participation include lack of time, lack of resources, trial-specific issues, communication difficulties, conflicts between the role of clinician and scientist, inadequate research experience and training for physicians, lack of rewards and recognition for physicians, and sometimes a scientifically uninteresting research question, among others. Strategies to encourage physician participation in clinical research include financial and nonfinancial incentives, adequate training, research questions that are in line with physician interests and have clear potential to improve patient care, and regular feedback. Finally, encouraging research culture and fostering the development of inquiry and research-based learning among medical students is now a high priority in order to develop more and better clinician-researchers.
\end{abstract}

Keywords: physician, clinical research, clinical trial, medical education

\section{Introduction}

... the mind is not a vessel to be filled, but a fire to be kindled.

(Plutarch, ca 46-127 AD)

In recent years, a paradigm shift has been noticed from experience-based to evidence-based practice in medicine and education. ${ }^{1-3}$ Research is the cornerstone of evidence-based medical practice, which translates new knowledge and technological capability into powerful tools for prevention and treatment of disease. ${ }^{4}$ Published research studies, especially landmark trials, have resulted in major changes in
Correspondence: Sayeeda Rahman Department of Clinical Sciences, School of Life Sciences, University of Bradford,

West Yorkshire, Bradford BD7 IDP, UK Tel +44 I274 236283

Fax +44I 274235600

Email seempi2005@yahoo.co.uk which permits unrestricted noncommercial use, provided the original work is properly cited. 
medical education and practice. ${ }^{1}$ Clinical trials offer 'a way to pool controlled observations in an objective and scientific way, allowing clinicians to decide with the best available data what therapy will work best for each patient'. ${ }^{1}$ The rapid development of new drugs, therapies, and devices has created a dramatic increase in the number of clinical research projects, and one of the key challenges to conducting a research project is recruiting the target sample size within a stipulated timescale. To meet these challenges, there is a need for greater participation in research by the physicians, including clinicians, as well as patients.

There is a growing concern that many countries, especially the developing world, have not been exploiting the enormous research potential offered by health care services. It has been observed that most clinical research fails to meet its recruitment targets. For example, multicenter trials funded by Health Technology Assessment (HTA) and Medical Research Council (MRC) in the United Kingdom showed that $45 \%$ failed to reach $80 \%$ of the target; less than half of participating clinicians succeeded in recruiting any patients. ${ }^{5,6}$ Commercial trials also reported similar problems: $30 \%$ of sites failing to recruit a single patient and $70 \%$ failing to meet agreed recruitment targets. ${ }^{7}$ A study demonstrated that $50 \%-80 \%$ of eligible patients are not recruited in clinical trials because of their doctors' decision not to offer the trial to that patient. ${ }^{8}$ An analysis of 333 randomized controlled trials (RCTs) conducted in the United Kingdom between 1971 and 2000 revealed that just over one-half failed to recruit the desired sample size, one-fifth recruited at least $75 \%$ of the target sample, while a further fifth recruited $<25 \%$ of the planned number of patients. ${ }^{9}$ It is also worrying that the number of physicians pursuing a career in research has also declined $^{10,11}$ and 'physician-scientist' has now become an 'endangered species'. ${ }^{12}$ There is clearly a need to examine why both physicians and patients are reluctant to take part in clinical research. Problems in patient recruitment to a trial may limit the statistical power of the trial to detect a treatment effect, ${ }^{13,14}$ and the reduction in statistical power is considered one of the main reasons for abandoning trials early. ${ }^{15,16}$ In addition, a less representative sample size also reduces the external validity of the trial. ${ }^{13}$ All these problems may thus delay the potential introduction of new treatments and more detailed evaluation of existing ones. ${ }^{13}$

Physician-researchers can act as 'double agents' who can enrich the quality of both services and research studies. Although clinical research is considered the key to the advancement of medical knowledge, physicians face a variety of barriers with regard to participation in clinical research and trials. ${ }^{4}$ All physicians should receive education and training in the fundamentals of research design and methodology, which need to be incorporated into undergraduate medical education and postgraduate training curricula and reinforced through continuing medical education. ${ }^{17}$ This article examines the barriers to and benefits of physician participation in clinical research and interventions needed to increase physician participation, including the specific role of undergraduate medical education.

\section{Barriers to participation in clinical research}

Many factors related to physician, patient, and trial characteristics may influence participation of physicians in clinical research. ${ }^{13,15,18-21}$ The barriers that physicians usually encounter in conducting clinical research are highlighted in many studies. ${ }^{13,16,21,22}$ Fayter et al ${ }^{13,18}$ identified these barriers as system-, organization-, research-, and physician-related. The details of the barriers are highlighted in Table 1.

Ross et $\mathrm{a}{ }^{15}$ conducted the most comprehensive systematic review related to barriers to participation in RCTs for cancer and other illnesses and identified lack of time as a major barrier. Ellis et $\mathrm{al}^{20}$ examined the barriers to participation in clinical trials for early breast cancer among Australian cancer specialists and identified lack of resources and issues related to specific trials as the major barriers. Another survey ${ }^{23}$ conducted among 357 clinicians to examine their attitudes to clinical trials of cancer therapy identified constraints imposed by the health care system which impede trial participation, including lack of time, communication difficulties, and conflicts between the role of clinician and scientist. Dev et $\mathrm{al}^{4}$ examined the factors influencing the participation of gastroenterologists and hepatologists in clinical research and identified the greatest barrier to participation in clinical research as lack of adequate resources.

Clinical practice and management duties deter physicians from participating in research. ${ }^{21,24-26}$ Time demands of recruitment, the consent process, and follow-up in trials, and additional management and administrative duties may also be considered as barriers. ${ }^{26-29}$ Physicians' inadequate research experience and training ${ }^{26,30-33}$ and lack of support staff $24,25,34,35$ are also blamed for poor participation.

There is a concern that research may alter the doctor-patient relationship, ${ }^{15,36}$ and physicians' rapport with patients may be damaged by participation in research/trials..$^{27,30,36}$ The main issues highlighted were the difficulty for clinicians of admitting that they do not know which treatment is best $\mathrm{t}^{29,30}$ and the perceived conflict between the clinician role and 
Table I Barriers to physician participation in clinical research and trials $4,7,8,17,19-23$

System-related and organization-related barriers

- Time involvement

- Extra research-related work

- Discussions with patients

- Grant applications and ethics submissions

- Resource issues

- Costs involved in research participation

- Facilities and infrastructure

- Inadequate administrative support

- Clerical activities/paperwork

- Inadequate provision of data management facilities

- Lack of staff and training

- Bureaucracy

- Requirements of funders and sponsors

- Culture of health care organizations: prioritizing clinical work over research

- Consent interviews

- Identifying patients (insufficient number available, competition from other trials, restricted eligibility criteria)

Trial design-related barriers

- Lack of clinical and scientific rationale of research

- Inappropriate study question

- Less visible potential to improve patient care

- Inappropriate standard therapy arm

- Minimal impact on clinical practice

- Increasing complexity of trials

- Excessive trial costs not covered by the trial sponsor

- Inferior trial medications compared to standard therapy

- Difficulty in obtaining funding

- Complex grant process

- Problem in obtaining informed consent

- Gatekeeping on behalf of the patients

- Not interested in participating in sponsored clinical research

- Difficulty in accessing the appropriate patient population

- Problems specific to recruitment of ethnic minority patients

Physician-related barriers

- Field, setting, and academic profile of physicians

- Lack of interest of physicians in the research topic

- Limited familiarity with research methods and procedures

- Disruption to clinical practice

- Loss of professional autonomy

- Role conflict of clinician and scientist

- Uncertainty inherent in clinical research

- Potential side effects

- Lack of awareness of ongoing trials

- Negative effect on doctor-patient relationship

- Gatekeeping because of bias for/against treatment arm

- Gatekeeping on behalf of the patients

- Lack of degree of recognition

- Inadequate financial compensation

the research (or scientific) role. ${ }^{37-39}$ Sometimes concerns regarding patients may affect physicians' decision to take part in a research trial, which include treatment toxicity or side effects, ${ }^{24,40}$ patients' travel time and cost, ${ }^{8,24,27}$ recruitment of more severely ill patients, ${ }^{41}$ and the effectiveness of treatment patients receive. ${ }^{33}$ Other barriers include loss of clinical autonomy, including loss of decision-making power and independence, being accountable to a third party, and restriction of the ability to individualize patient care. ${ }^{15,21,29-32,37,38}$ Some studies mentioned that lack of rewards and recognition is a deterrent to physician participation. ${ }^{15,24,31-33}$ Scientifically uninteresting trials and research questions may sometimes fail to attract physicians to research. ${ }^{15,24,33}$

\section{Strategies to encourage physician participation in clinical research}

In the absence of physician scientists, the bridge between

bench and bedside will weaken, perhaps even collapse.

Dr Leon Rosenberg

To encourage physician participation in clinical research, organizational and operational infrastructures need to be strengthened by establishing effective relationships among structure, process, and outcome of research planning and management process. ${ }^{42}$ Effective operational and organizational structures are needed to encourage physician participation in research and these are summarized in Table 2.

\section{Resources}

Financial incentives have been shown to be among the most important factors motivating physician involvement in research. ${ }^{43-45}$ Clinical research and industry-sponsored trials in particular, which often carry greater reimbursement, are now viewed as essential sources of income for the maintenance of research programs and staff., ${ }^{4,46}$ Research also indicates that academic-industry relationships in medicine have substantial benefits for industry sponsors and that the rate of industry support for clinical research is likely to increase in future. ${ }^{4,47}$

\section{Training clinician researchers}

Physicians need adequate training in research methodology and biostatistics in order to build research skills on 'core' clinical knowledge. ${ }^{22}$ Need-based training will help role integration of care providers and scientists and will develop physicians to become patient-oriented clinician-researchers. Research fellowships and mentoring programs, research bursaries, and workshops/seminars intended for physicians will help to develop appropriate understanding of research and will provide opportunities to work with research groups and role models to discuss the practical issues of conducting clinical research. Appropriate provisions should be adopted to integrate research methodology in undergraduate education, 
Table 2 Operational and organizational structures needed to encourage physician participation in research

\begin{tabular}{lll}
\hline Structure & Process & Outcome \\
\hline Resources & Policy and procedures & Influence care for patients and their families \\
Human & Publications of guidelines & Improve patients' lives \\
Financial & Time management & Encourage professional growth and development \\
Research environment and infrastructures & Reimbursement & Recruit and retain jobs \\
Structures and forums & Reward and recognition & Generate more resources and funds for medical \\
Research committee & Involvement in research committee & schools and health care organizations \\
Network & Create internal expertise of clinical leadership & \\
Academic-industry-national & Establish research groups & \\
hospital service relationships & Collaborate with other organizations & \\
Training and teaching & Promote evidence-driven practice & \\
Fellowship & Rapid learning health care system & \\
Mentored program & Research in undergraduate medical curricula & \\
Seminar/workshop & & \\
Research bursaries & & \\
\hline
\end{tabular}

postdoctoral training, career awards, and intensive training conferences. Physicians can be encouraged to undertake appointments in out-of-program research, leading to a higher degree, usually a PhD. ${ }^{48}$ The dual-degree programs MD-PhD or $\mathrm{MD}-\mathrm{MPH}^{49}$ in the United States, and NIHR Academic Clinical Fellowships (50\% of time undertaking research or educationalist training) and NIHR Clinical Lectureships ( $50 \%$ of time) in the United Kingdom ${ }^{50}$ can be widely used in other countries to produce physician-researchers to handle a growing number of clinical research studies. In Singapore, a program has been launched to encourage doctors under specialty training to pursue a higher degree in research (either a 3- to 4-year $\mathrm{PhD}$ or a 1-year MSc) in order to equip them with research knowledge and skills that would allow them to develop translational research parallel to their clinical careers in the long term. ${ }^{51}$ Programs can be specifically designed to encourage the practicing physician (including private or academic clinical practice) to engage in clinical research while maintaining an active role in clinical practice, for example, the Clinical Research/Reproductive Scientist Training Program supported by the National Institute of Child Health and Human Development, Duke University, and the American Society for Reproductive Medicine. ${ }^{12}$ All these will help physicians to relate clinical experience to research and research knowledge to clinical work.

\section{Creating research environment}

The contention, 'doctors simply don't want to take part in clinical trials', ${ }^{52}$ is not true. Studies showed that physicians are eager to participate in clinical research if an adequate trial infrastructure and environment is present. ${ }^{19-22}$ To ensure physician participation in clinical research, an organizational culture needs to be developed that values research and nourishes evidence-based medicine and practice. A 'centralized support services' organization outside the physician group should facilitate the business of research by undertaking the clerical and other administrative tasks, including human subject approvals, institutional agreements, progress reports to funding agencies, and communications among the research team. ${ }^{4,19,21,22}$ This will create a research environment that will ensure patient safety, increase economic and medical efficiency, and promote a more standardized and regulatory-compliant process for conducting clinical research. ${ }^{4}$ Physician-focused structures and forums, research groups, and networks should be created within the academic and health care organizations and appropriate collaboration with industry should be established to secure research funds.

\section{Motivation for research participation}

To facilitate physician participation, the research topic/area should be in-line with physician interest, relevant and important to their field, linked to the real world of clinical practice, and above all, should have clear potential to improve patient care. ${ }^{12,19,45,51,53}$ Research activities integrated into the usual patterns of patient care which do not interfere with the flow of patient care increase the likelihood of physician participation. ${ }^{19}$ As mentioned earlier, there should be a responsible party to handle the logistics and deal with research-related problems and issues. ${ }^{419,21,22}$ This will ensure minimal impact on clinical practice. Regular feedback and support along with financial compensation will motivate physicians to participate in clinical research. ${ }^{19,53,54}$ Feedback regarding the progress and the degree of achievement of goals will help busy clinicians to assess their contributions and to maintain enthusiasm for the research. ${ }^{19}$

\section{Policies and guidelines}

There is a need for developing appropriate policies for managing time for the physicians to minimize interference with 
clinical commitments and for payments and recognition for physician involvement in research. To manage time, appropriate provision for research administrative support should be established with efficient use of a study coordinator and other staff., ${ }^{4,22}$ Reward and recognition should include financial and nonfinancial incentives; ${ }^{19,55}$ financial recognition usually includes pay increases, promotion, grants for attending conferences, etc, and nonfinancial incentives include formal institutional recognition/awards, news in the institute's newsletters, news in the local media, coauthorship, etc. Financial incentives have 'symbolic' and 'material' significance which highlight the importance of the research. ${ }^{19}$

\section{Benefits of clinical research}

Clinical research provides benefits to physicians, patients, health care organizations, and the country as a whole.

\section{Benefits to physicians}

A clinician-researcher is considered to be an important figure in health research and emphasis has been given to involving more clinicians in patient-oriented research. ${ }^{53}$ Clinical research contributes to the expanding knowledge base of medicine and provides physicians an opportunity to offer patients latest cutting-edge therapies. ${ }^{1,56}$ Participation opens their eyes to medical innovation, and they are benefited by satisfying intellectual curiosity, increasing research provisions, and assisting career advancement. ${ }^{56}$ Participation in clinical research may add prestige to physicians' practice or institution. ${ }^{1}$ A study conducted in the United States showed that a substantial number of physicians engaged in pharmaceutical industry-sponsored clinical trials and/or lectures in an effort to supplement their incomes as well as enhance their prestige, knowledge, and professional reputation. ${ }^{45}$

\section{Benefits to patients}

Clinical research offers patients access to cutting-edge therapy, which could be lifesaving in addition to providing them with state-of-the-art quality care. ${ }^{56}$ It plays an important role in improving the diagnosis and treatment of diseases and quality of life of the patients and people. Research has resulted in hundreds of innovations that offer earlier diagnosis of illness, result in better outcomes, and minimize side effects, including less demanding administration regimes. Clinical research may also provide direct benefits for those patients involved in clinical trials due to patients receiving closer medical attention and better follow-up and continuity of care. There is substantial evidence that participation in clinical research, irrespective of whether enrolment is in the placebo or in the treatment arm, improves health outcomes. ${ }^{57}$

\section{Operational and financial benefits to health care organizations}

Research helps hospitals ${ }^{58}$ and educational institutes ${ }^{59}$ with additional funding for capacity building in core academic, clinical, and research activities. Hospitals usually receive reimbursements for participating in clinical trials, either in cash, equipments, or additional staff. In India, for example, Pfizer has donated a US $\$ 100,000$ bone density testing machine to each of six hospitals to investigate its osteoporosis drug. ${ }^{57}$ Pharmaceutical companies support high-profile one-off investments for setting-up clinical laboratory and other large-scale research facilities, for example, GlaxoSmithKline’s $£ 72$ million investment in Imperial College London's Clinical Imaging Centre. ${ }^{58}$ In addition, industry collaborations sometimes contribute part of the overall hospital budget that provides infrastructure, part funding of personnel, day-to-day activities, and other subsidies. For example, $2 \%$ of the overall budget of Royal Marsden, specialist cancer hospital in the United Kingdom, comes from industry collaborations. ${ }^{58}$

\section{Scientific benefits to health care organizations}

The clinician-researcher is able to make an important contribution to the quality of clinical services by facilitating an interactive flow of ideas between the clinical and research fields and disseminating evidence-based treatment approaches. ${ }^{53}$ Physicians have the opportunities to attract funds and resources through research grants, and this ultimately helps health care organizations to retain their talents, knowledge, and skills in a competitive global economy.

\section{Overall economic and strategic benefits}

The economic opportunities created by clinical research draw more talented people into the medical profession in a country. The scope for clinical trials is increasing in developing countries $^{60}$ and opens the door for wider employment opportunities. Clinical research creates employment for site personnel, study monitors, and ancillary services, with an economic impact on the whole community. In 2003, the UK pharmaceutical industry had a trade surplus of $£ 3.6$ billion and has been shown to have an employment multiplier effect of 6.7 and an economic contribution multiplier of 3.9. ${ }^{58}$ It is estimated that the Indian clinical research industry will attract US $\$ 1.5$ billion of revenue from international sponsors by 2010 which 
will create job demands for $\sim 10,000$ investigators and 50,000 clinical research professionals. ${ }^{61}$

\section{Research in medical curricula: implications for future physician-scientist}

... undergraduate research should ... be at the center of

the undergraduate experience.

Hodge (2007)

The 'teaching-research nexus' should be central to medical education. ${ }^{62}$ Research training should be considered an essential component in an innovative undergraduate medical curriculum. ${ }^{54,59,63-66}$ This issue is crucial as medical research is not given high priority by the medical and scientific community. ${ }^{67-71}$ The research activities should be boosted by incorporating research methodology in medical curricula, appointing researchers in clinical and academic departments, and allocating more funds to conduct research. A study reported that medical students are largely unaware of the research activities in their host institution ${ }^{59}$ and it is emphasized that adequate training should be provided on research methodology and biostatistics. ${ }^{72}$ There has been much discussion regarding the decline in medical graduates choosing clinician-scientist careers and decrease of physician-scientists in medical practice..$^{67,73-78}$ Encouraging research culture and fostering the development of inquiry and research-based learning among medical students are now a high priority. ${ }^{79-81} \mathrm{~A}$ recent review conducted by Bierer and $\mathrm{Chen}^{82}$ has shown that engaging in research projects can influence students' choice of clinical specialty or interest in research. Various authorities strongly emphasized the development of research-specific skills among undergraduate medical students along with other transferable skills. ${ }^{63,83} \mathrm{To}$ address this issue effectively, a research-informed approach to pedagogic development should be undertaken in medical schools to establish a sustainable link between teaching and research. In recent years, an increasing number of medical schools have implemented or are considering implementing structured research activities. ${ }^{8,59,77,84-89}$ Research involvement should be an obligatory part of medical schools' curricula, ${ }^{67,71}$ for example, involving medical students in designing and implementing research studies (Aga Khan University, Paki$\left.\operatorname{stan}^{68}\right)$, awarding medical degrees to medical students only after they have authored a research project $\left(\right.$ Germany $\left.{ }^{89}\right)$, the Medical Student Research Fellowship (MSRF) Program (United States), ${ }^{77}$ Duke Clinical Research Fellowship (CRF) program (United States) ${ }^{84}$ Norwegian Medical Student Research Programme, ${ }^{85}$ student selected components (SSC) program (United Kingdom), ${ }^{88}$ and introducing dual-degree programs (MD-PhD, MD-MPH, United States). ${ }^{49}$ The Mount Sinai School of Medicine (United States) established

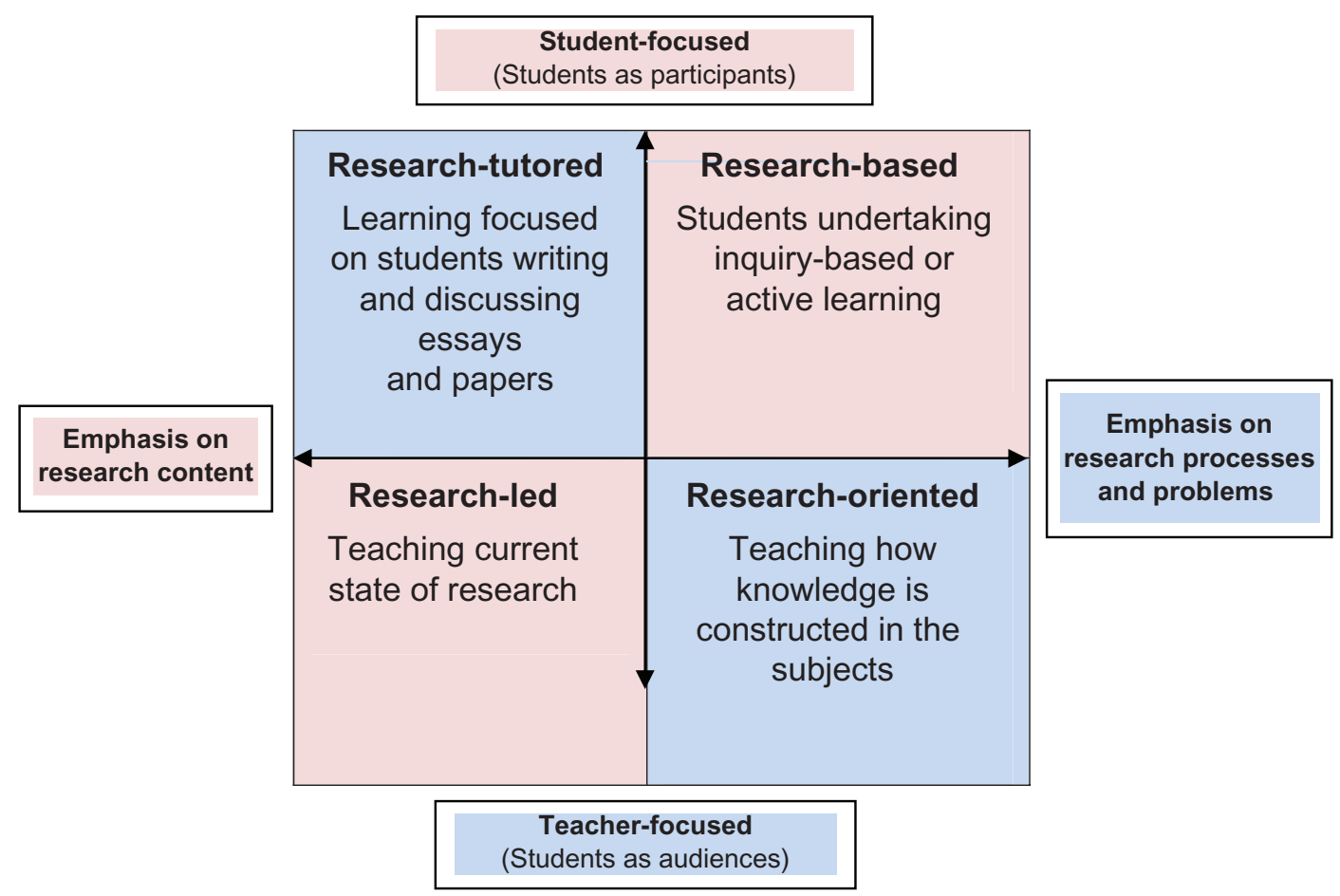

Figure I Curriculum design and the research-teaching nexus. ${ }^{91}$ 
a multifaceted research program to encourage students to involve basic or patient-oriented research, provide information about available research opportunities, help students in obtaining financial support from existing sources and developing new sources, implement strategies to reward student participation in research, and create new and innovative programs..$^{90}$ It is also important to examine ways to increase faculty involvement in student research. This can be encouraged through formal training in student supervision and protection of faculty time for student project work. ${ }^{59}$

Medical schools should analyze current practices of teaching-learning and research while reflecting upon possible changes to develop a research culture using the model proposed by Healey and Jerkins ${ }^{91}$ (Figure 1). The model suggested four main ways of engaging undergraduates with research and inquiry: ${ }^{92}$

- Research-led: learning about current research in the discipline.

- Research-oriented: developing research skills and techniques.

- Research-based: undertaking research and inquiry.

- Research-tutored: engaging in research discussions.

This model has two axes: one classifies the ways students may be engaged in research and inquiry according to the extent to which students are treated primarily as the audience or as participants, while the second axis classifies the approach as emphasizing research content or research processes and problems. All four ways of engaging students with research and inquiry are valid and valuable, and it is advocated that curricula should contain elements of all of them. ${ }^{92}$ In medical schools, relatively too much teaching and learning is in the bottom half of the model, and most students would benefit from spending more time in the top half. However, students should not spend nearly all their time in the top half, as tends to happen in some problem-based learning curricula. ${ }^{92}$

\section{Conclusion}

Physician-researchers can serve as effective 'bridges' between the research and practice communities and can facilitate both development of clinically relevant research and dissemination of evidence-based treatments into routine clinical services. The organization should have adequate structure to support process and achieve outcomes. A well-planned implementation of these structures is likely to encourage clinicians to participate in clinical research. In addition, medical schools should develop effective institutional strategies and policies to highlight student awareness and experience of undergraduate research and inquiry using the following strategies:

- Embed research in the mission and vision of the medical school.

- Link undergraduate research and inquiry to institutional policies.

- Develop supportive institutional curricula frameworks and structures.

- Develop student-focused teaching, learning, and research policies.

- Embed undergraduate research and inquiry from the first day students enter medical schools.

- Raise student awareness of research and create a research environment.

- Provide opportunities for all students to undertake undergraduate research and inquiry within and outside the curriculum.

\section{Acknowledgement}

The authors would like to thank the Open University Press for copyright permission to use Figure 1.

\section{Disclosure}

The authors report no conflicts of interest in this work.

\section{References}

1. Lader EW, Cannon CP, Ohman EM, et al; American College of Cardiology Foundation. The clinician as investigator: participating in clinical trials in the practice setting. Circulation. 2004;109(21): 2672-2679.

2. Harden RM, Lilley PM. Editorial: best evidence medical education: the simple truth. Med Teach. 2000;22(2):117-119.

3. Hart IR, Harden RM. Best evidence medical education (BEME): a plan for action. Med Teach. 2000;22(2):131-135.

4. Dev AT, KaufTL, Zekry A, et al. Factors influencing the participation of gastroenterologists and hepatologists in clinical research. BMC Health Serv Res. 2008;8:208.

5. Jack WJ, Chetty U, Rodger A. Recruitment to a prospective breast conservation trial: why are so few patients randomised? BMJ. 1990; 301(6743):83-85.

6. Peto V, Coulter A, Bond A. Factors affecting general practitioners' recruitment of patients into a prospective study. Fam Pract. 1993;10(2): 207-211.

7. Department of Health. Clinical Research Report: Pharmaceutical Industry Competitive Task Force (PICTF). 2002. Available from: http:// www.advisorybodies.doh.gov.uk/pictf/clinicalresearch.htm. Accessed November 18, 2010.

8. Benson AB 3rd, Pregler JP, Bean JA, Rademaker AW, Eshler B, Anderson K. Oncologists' reluctance to accrue patients onto clinical trials: an Illinois Cancer Center study. J Clin Oncol. 1991;9(11):2067-2075.

9. Vale C, Stewart L, Tierney J; UK Coordinating Committee for Cancer Research National Register of Cancer. Trends in UK cancer trials: results from the UK Coordinating Committee for Cancer Research National Register of Cancer Trials. Br J Cancer. 2005;92(5):811-814.

10. DeMaria AN. Clinical investigation ... an impending crisis? J Am Coll Cardiol. 2003;41(11):2100-2101. 
11. Eastman P. Number of US physicians participating in clinical research continuing to drop (Association of Clinical Research Organizations Survey). Oncology Times. 2010;32(14):21-23.

12. Armstrong AY, Decherney A, Leppert P, Rebar R, Maddox YT. Keeping clinicians in clinical research: the Clinical Research/Reproductive Scientist Training Program. Fertil Steril. 2009;91(3):664-666.

13. Fayter D, McDaid C, Eastwood A. A systematic review highlights threats to validity in studies of barriers to cancer trial participation. J Clin Epidemiol. 2007;60(10):990-1001.

14. Baum M. The ATAC (Arimidex, Tamoxifen, Alone or in Combination) adjuvant breast cancer trial in postmenopausal patients: factors influencing the success of patient recruitment. Eur J Cancer. 2002;38(15): 1984-1986.

15. Ross S, Grant A, Counsell C, Gillespie W, Russell I, Prescott R. Barriers to participation in randomised controlled trials: a systematic review. $J$ Clin Epidemiol. 1999;52(12):1143-1156.

16. Holden G, Rosenberg G, Barker K, Tuhrim S, Brenner B. The recruitment of research participants: a review. Soc Work Health Care. 1993; 19(2):1-44.

17. Chen DT, Miller FG, Rosenstein DL. Clinical research and the physician-patient relationship. Ann Intern Med. 2003;138(8): 669-672.

18. Fayter D, McDaid C, Ritchie G, Stirk L, Eastwood A. Systematic Review of Barriers, Modifiers and Benefits Involved in Participation in Cancer Clinical Trials. York (UK): Centre for Reviews and Dissemination; 2006. CRD Report 31.

19. Albers LL, Sedler KD. Clinician perspectives on participation in research. J Midwifery Womens Health. 2004;49(1):47-50.

20. Ellis PM, Butow PN, Simes RJ, Tattersall MH, Dunn SM. Barriers to participation in randomized clinical trials for early breast cancer among Australian cancer specialists. Aust N Z J Surg. 1999;69(7):486-491.

21. Yanagawa H, Kishuku M, Akaike M, Azuma H, Irahara M. View of physicians on and barriers to patient enrollment in a multicenter clinical trial: experience in a Japanese rural area. Int Arch Med. 2010;3:7.

22. Sumi E, Murayama T, Yokode M. A survey of attitudes toward clinical research among physicians at Kyoto University Hospital. BMC Med Educ. 2009;9:75.

23. Fallowfield L, Ratcliffe D, Souhami R. Clinicians' attitudes to clinical trials of cancer therapy. Eur J Cancer. 1997;33(13):2221-2229.

24. Foley JF, Moertel CG. Improving accrual into cancer clinical trials. J Cancer Educ. 1991;6(3):165-173.

25. Smyth JF, Mossman J, Hall R, et al. Conducting clinical research in the new NHS: the model of cancer. United Kingdom Coordinating Committee on Cancer Research. BMJ. 1994;309(6952):457-461.

26. Dickinson CJ. Clinical research in the NHS today. J R Coll Physicians Lond. 1994;28(5):460-463.

27. Fisher WB, Cohen SJ, Hammond MK, Turner S, Loehrer PJ. Clinical trials in cancer therapy: efforts to improve patient enrollment by community oncologists. Med Pediatr Oncol. 1991;19(3):165-168.

28. Schaeffer MH, Krantz DS, Wichman A, Masur H, Reed E, Vinicky JK. The impact of disease severity on the informed consent process in clinical research. Am J Med. 1996;100(3):261-268.

29. Taylor KM, Margolese RG, Soskolne CL. Physicians' reasons for not entering eligible patients in a randomized clinical trial of surgery for breast cancer. N Engl J Med. 1984;310(21):1363-1367.

30. Taylor KM, Kelner M. Interpreting physician participation in randomized clinical trials: the Physician Orientation Profile. J Health Soc Behav. 1987;28(4):389-400.

31. Taylor KM. Physician participation in a randomized clinical trial for ocular melanoma. Ann Ophthalmol. 1992;24(9):337-344.

32. Taylor KM, Feldstein ML, Skeel RT, Pandya KJ, Ng P, Carbone PP. Fundamental dilemmas of the randomized clinical trial process: results of a survey of the 1,737 Eastern Cooperative Oncology Group investigators. J Clin Oncol. 1994;12(9):1796-1805.

33. Tognoni G, Alli C, Avanzini F, et al. Randomised clinical trials in general practice: lessons from a failure. BMJ. 1991;303(6808):969-971.
34. Shea S, Bigger JT Jr, Campion J, et al. Enrollment in clinical trials: institutional factors affecting enrollment in the cardiac arrhythmia suppression trial (CAST). Control Clin Trials. 1992;13(6): 466-486.

35. Morse EV, Simon PM, Besch CL, Walker J. Issues of recruitment, retention, and compliance in community-based clinical trials with traditionally underserved populations. Appl Nurs Res. 1995;8(1): 8-14.

36. Maslin-Prothero SE. Factors Affecting Recruitment to Breast Cancer Clinical Trials. An Examination of the British Association of Surgical Oncology II Trial and the International Breast Cancer Intervention Study. Nottingham (UK): Nottingham University; December 2000.

37. Taylor KM, Shapiro M, Soskolne CL, Margolese RG. Physician response to informed consent regulations for randomized clinical trials. Cancer. 1987;60(6):1415-1422.

38. Taylor KM. Integrating conflicting professional roles: physician participation in randomized clinical trials. Soc Sci Med. 1992;35(2):217-224.

39. Siminoff LA, Fetting JH, Abeloff MD. Doctor-patient communication about breast cancer adjuvant therapy. J Clin Oncol. 1989;7(9): $1192-1200$

40. Winn RJ, Miransky J, Kerner JF, Kennelly L, Michaelson RA, Sturgeon SR. An evaluation of physician determinants in the referral of patients for cancer clinical trials in the community setting. Prog Clin Biol Res. 1984;156:63-73.

41. Antman K, Amato D, Wood W, et al. Selection bias in clinical trials. J Clin Oncol. 1985;3(8):1142-1147.

42. Gawlinski A. The power of clinical nursing research: engage clinicians, improve patients' lives, and forge a professional legacy. Am J Crit Care. 2008;17(4):315-326.

43. Prescott RJ, Counsell CE, Gillespie WJ, et al. Factors that limit the quality, number and progress of randomised controlled trials. Health Technol Assess. 1999;3(20):1-143.

44. Keinonen T, Keränen T, Klaukka T, Saano V, Ylitalo P, Enlund H. Investigator barriers and preferences to conduct clinical drug trials in Finland: a qualitative study. Pharm World Sci. 2003;25(6):251-259.

45. Ashar BH, Miller RG, Getz KJ, Powe NR. Prevalence and determinants of physician participation in conducting pharmaceutical-sponsored clinical trials and lectures. J Gen Intern Med. 2004;19(11):1140-1145.

46. Blumenthal D. Academic-industrial relationships in the life sciences. N Engl J Med. 2003;349(25):2452-2459.

47. Blumenthal D, Campbell EG, Causino N, Louis KS. Participation of life-science faculty in research relationships with industry. $N$ Engl $J$ Med. 1996;335(23):1734-1739.

48. NHS Education for Scotland. Scottish Clinical Research Excellence Development Scheme (SCREDS): A Guide to the Scheme. 2009. Available from: http://www.nes.scot.nhs.uk/media/4911/scredsfinalre visedguidetoscheme16thjanuary09.pdf. Accessed December 18, 2010.

49. Association of American Medical Colleges. Available from: http:// www.aamc.org/students/considering/exploring_medical/research/ mdphd/. Accessed December 18, 2010.

50. National Institute for Health Research. NIHR Integrated Academic Training Programme. Available from: http://www.nihrtcc.nhs.uk/ intetacatrain/. Accessed December 18, 2010.

51. Salto-Tellez M, Oh VM, Lee EH. How do we encourage clinician scientists in Singapore? Ann Acad Med Singapore. 2007;36(11):879-880.

52. McCurry J. Japan unveils 5-year plan to boost clinical research. Lancet. 2007;369(9570):1333-1336.

53. Yanos PT, Ziedonis DM. The patient-oriented clinician-researcher: advantages and challenges of being a double agent. Psychiatr Serv. 2006;57(2):249-253.

54. Lloyd T, Phillips BR, Aber RC. Factors that influence doctors' participation in clinical research. Med Educ. 2004;38(8):848-851.

55. Thomas PA, Diener-West M, Canto MI, Martin DR, Post WS, Streiff MB. Results of an academic promotion and career path survey of faculty at the Johns Hopkins University School of Medicine. Acad Med. 2004;79(3):258-264. 
56. Jameson $\mathrm{S}$. The benefits and challenges of conducting clinical trials. Commun Oncol. 2006;3(3):163-167.

57. Maiti R, Raghavendra M. Clinical trials in India. Pharmacol Res. 2007;56(1):1-10.

58. UK Clinical Research Collaboration (UKCRC). Clinical Research in the UK: Towards a Single System that Reliably Delivers Distinctive Quality and Rapid Access at Reasonable Cost (The McKinsey Report). 2005. Available from: http://www.ukcrc.org/publications/reports.aspx. Accessed December 18, 2010.

59. Burgoyne LN, O’Flynn S, Boylan GB. Undergraduate medical research: the student perspective. Med Educ Online. 2010;15:5212.

60. Rashid A. Global clinical trials in Bangladesh: a call for action. BAPA J. 2006;15:26-31.

61. White Paper on Global Clinical Trials in India: Prospects and Challenges. BioBusiness Summit 2005; 2005 Nov 14-15; Federation House, FICCI, New Delhi, India.

62. Jenkins A, Healey M, Zetter R. Linking Teaching and Research in Disciplines and Departments. York (UK): Higher Education Academy; 2007.

63. General Medical Council. Tomorrow's Doctors Education: Outcomes and Standards for Undergraduate Medical Education. UK: General Medical Council; 2009.

64. Simpson JG, Furnace J, Crosby J, et al; The Scottish Deans' Medical Curriculum Group. The Scottish doctor - learning outcomes for the medical undergraduate in Scotland: a foundation for competent and reflective practitioners. Med Teach. 2002;24(2):136-143.

65. Illing J. Thinking About Research: Frameworks, Ethics and Scholarship. Edinburgh (UK): ASME; 2007.

66. World Federation for Medical Education. International standards in medical education: assessment and accreditation of medical schools' - educational programmes. A WFME position paper. The Executive Council, The World Federation for Medical Education. Med Educ. 1998;32(5):549-558.

67. Majumder MAA. Issues and priorities of medical education research in Asia. Ann Acad Med Singapore. 2004;33(2):257-263.

68. Khan H, Khawaja MR, Waheed A, Rauf MA, Fatmi Z. Knowledge and attitudes about health research amongst a group of Pakistani medical students. BMC Med Educ. 2006;6:54.

69. Khan H, Khan S, Iqbal A. Knowledge, attitudes and practices around health research: the perspective of physicians-in-training in Pakistan. BMC Med Educ. 2009;9:46.

70. Pai SA. Career preferences of medical students who joined Grant Medical College, Bombay in 1957 and 1982. Natl Med J India. 2009;22(3):121-123.

71. Aslam F, Shakir M, Qayyum MA. Why medical students are crucial to the future of research in South Asia. PLoS Med. 2005;2(11):e322.

72. Murdoch-Eaton D, Drewery S, Elton S, et al. What do medical students understand by research and research skills? Identifying research opportunities within undergraduate projects. Med Teach. 2010;32(3):e152-e160.

73. Wyngaarden JB. The clinical investigator as an endangered species. N Engl J Med. 1979;301(23):1254-1259.
74. Gill NG. The end of the physician scientist? Am Sch. 1984;53: 353-368.

75. Rosenberg LE. The physician-scientist: an essential - and fragile-link in the medical research chain. J Clin Invest. 1999;103(12):1621-1626.

76. Ley TJ, Rosenberg LE. The physician-scientist career pipeline in 2005: build it, and they will come. JAMA. 2005;294(11):1343-1351.

77. Solomon SS, Tom SC, Pichert J, Wasserman D, Powers AC. Impact of medical student research in the development of physician-scientists. J Investig Med. 2003;51(3):149-156.

78. Siemens DR, Punnen S, Wong J, Kanji N. A survey on the attitudes towards research in medical school. BMC Med Educ. 2010;10:4.

79. Detsky ME, Detsky AS. Encouraging medical students to do research and write papers. CMAJ. 2007;176(12):1719-1721.

80. Boninger M, Troen P, Green E, et al. Implementation of a longitudinal mentored scholarly project: an approach at two medical schools. Acad Med. 2010;85(3):429-437.

81. Parsonnet J, Gruppuso PA, Kanter SL, Boninger M. Required vs elective research and in-depth scholarship programs in the medical student curriculum. Acad Med. 2010;85(3):405-408.

82. Bierer SB, Chen HC. How to measure success: the impact of scholarly concentrations on students - a literature review. Acad Med. 2010;85(3):438-452.

83. National Alliance for Physician Competence. Good Medical PracticeUSA: The National Alliance. Version 1.0. 2007. Available from: http:// www.gmpusa.org. Accessed December 18, 2010.

84. Gallin EK, Le Blancq SM; Clinical Research Fellowship Program Leaders. Launching a new fellowship for medical students: the first years of the Doris Duke Clinical Research Fellowship Program. J Investig Med. 2005;53(2):73-81.

85. Hunskaar S, Breivik J, Siebke M, Tømmerås K, Figenschau K, Hansen JB. Evaluation of the medical student research programme in Norwegian medical schools. A survey of students and supervisors. BMC Med Educ. 2009;9:43.

86. Van Eyk HJ, Hooiveld MHW, van Leeuwen TN, van der Wurff BLJ, De Craen AJM, Dekker FW. Scientific output of Dutch medical students. Med Teach. 2010;32(3):231-235.

87. Green EP, Borkan JM, Pross SH, et al. Encouraging scholarship: medical school programs to promote student inquiry beyond the traditional medical curriculum. Acad Med. 2010;85(3):409-418.

88. Robinson L, Drewery S, Ellershaw J, Smith J, Whittle S, Murdoch-Eaton D. Research governance: impeding both research and teaching? A survey of impact on undergraduate research opportunities. Med Educ. 2007; 41(8):729-736.

89. Diez C, Arkenau C, Meyer-Wentrup F. The German medical dissertationtime to change? Acad Med. 2000;75(8):861-863.

90. Zier K, Stagnaro-Green A. A multifaceted program to encourage medical students' research. Acad Med. 2001;76(7):743-747.

91. Healey M. Linking research and teaching to benefit student learning. J Geogr High Educ. 2005;29(2):183-201.

92. Healey M, Jenkins A. Developing Undergraduate Research and Inquiry. York (UK): Higher Education Academy; 2009.
Advances in Medical Education and Practice

\section{Publish your work in this journal}

Advances in Medical Education and Practice is an international, peerreviewed, open access journal that aims to present and publish research on Medical Education covering medical, dental, nursing and allied healthcare professional education. The journal covers undergraduate education, postgraduate training and continuing medical education
Dovepress

including emerging trends and innovative models linking education, research, and healthcare services. The manuscript management system is completely online and includes a very quick and fair peer-review system. Visit http://www.dovepress.com/testimonials.php to read real quotes from published authors. 